\title{
EFFECT OF L-CARNITINE ON THE GROWTH, SERUM COMPONENTS, CARCASS TRAITS AND HISTOLOGICAL STRUCTURE OF MUSCLES IN THE GROWING GEESE
}

\author{
Zenat, A. Ibrahiem ${ }^{1}$, W. Ezzat ${ }^{2}$, A.A. El- Zaiat ${ }^{2}$ and M.S. Shoeib ${ }^{2}$ \\ 1- Department of Poultry Production, Faculty of Agriculture, University of \\ Zagazig, 2- Animal Production Research Institute, Dokki, Giza, Egypt
}

\section{SUMMARY}

The present study was designed to investigate the effects of different levels $L$ carnitine on growth performance, fatty acids profile, skeletal muscles histology, serum biochemical traits and carcass characteristics of the growing geese. A total number of one hundred and twenty, tow-weeks-old geese chicks were used in the study. They were randomly distributed into four experimental groups of 30 chicks each 3 replicates pens containing 10 birds until 14 weeks of age. The treatments were; non-addition (control group), 50, 100, and $150 \mathrm{mg} / \mathrm{l}$ L-carnitine was administrated via drinking water. The results showed that the addition of L-carnitine in the drinking water of growing geese significantly $(P<0.05)$ increased body weight during 4, 6 and 8 weeks of age and weight gain from 2-4 and 4-6 weeks of age compared with the control group. However, no significant difference was observed with L-carnitine levels on body weight from 10 to 14 and weight gain from 6-14 weeks of age. Also, there was no significant difference in feed intake during the experimental period of all treatments. At all investigated periods, birds received 150 $\mathrm{mg} / \mathrm{L} \mathrm{L}$-carnitine recorded the best feed conversion ratio followed by birds received 100 and $50 \mathrm{mg} / \mathrm{l}$ L-carnitine compared to the control group. Carcass and liver percentage to live weight were significantly $(P<0.05)$ increased with L-carnitine levels. However, abdominal fat seemed to be lower with L-carnitine levels as compared with control group.

Myristic (C14:0) and palmitic (C16:0) acids of abdominal fat were significantly $(P<0.05)$ increased while, oleic (C18:1) and linolenic (C18:3) acids were significantly $(P<0.05)$ decreased by increasing the levels of $L$ - carnitine in the drinking water of geese. However, stearic (C18:0), palmitoliec (C16:1) and linoleic (C18:2) were not affected by L-carnitine level supplementation in the drinking water of geese.

Serum total protein, globulin, insulin-like growth factor-1 (IGF-1) and lactate dehydrogenase $(\mathrm{LDH})$ were significantly $(P \leq 0.01$ and 0.05$)$ increased while, total lipids and creatine phosphokinase (CPK) decreased by addition of $100 \mathrm{mg} / \mathrm{l} \mathrm{L}$ carnitine, respectively. Serum albumin, cholesterol, triglyceride, glucose, and $T_{3}$ were insignificantly affected by levels of L-carnitine added in the drinking water.

The results of histological studies revealed that L-carnitine could stimulate muscles growth in growing geese with a dose of $100 \mathrm{mg} / \mathrm{l} \mathrm{L}$-carnitine, however the over dose (above $100 \mathrm{mg} / \mathrm{l}$ L-carnitine) may cause an irregular growth pattern of some myofibers which many produce a course or dense muscle fibers. Histological studies of liver showed that L-carnitine supplementation in the drinking water has no significant effect on hepatic cells.

Keywords:L-carnitine, 